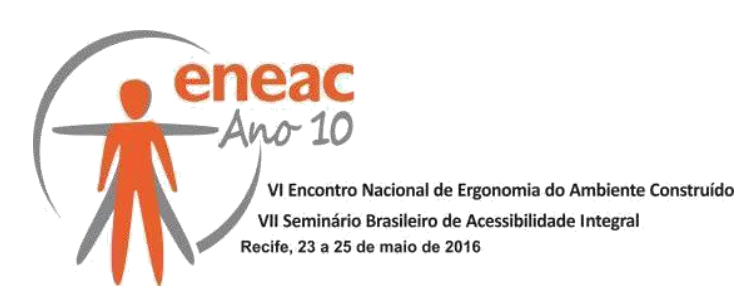

\title{
PERCEPÇÃO AMBIENTAL - A IMPORTÂNCIA DA OPINIÃO DOS USUÁRIOS NA GERAÇÃO DE RECOMENDAÇÕES PARA PROJETOS DE AMBIENTES CONSTRUÍDOS
}

\author{
TAVARES, Ademario Santos (1); \\ ALBUQUERQUE, Luiz Wilson Nunes de (2); \\ BARBOSA, André Henrique (3) \\ VILLAROUCO, Vilma (4); \\ (1) Unifavip - DeVry Brasil, Mestre em Design \\ e-mail: atavares@unifavip.edu.br \\ (2) Universidade Federal de Pernambuco, Especialista em Ergonomia \\ e-mail: ctiwilson@hotmail.com
}

(3) Centro Universitário Maurício de Nassau - UNINASSAU, Discente Arquitetura

e-mail: andrehenry2009@hotmail.com

(4) Universidade Federal de Pernambuco, Pós-Doutora Engenharia e Gestão Conhecimento

e-mail: villarouco@hotmail.com

\begin{abstract}
RESUMO
A percepção ambiental é um dos principais fomentadores de dados para uma correta leitura de um ambiente em uso. A interpretação dos depoimentos dos usuários é fundamental para otimizar ambiente e sistema. Após aplicar a MEAC na praça de alimentação de um shopping center, este artigo traz o resultado comparativo entre a interpretação dos dados físicos (através das 3 primeiras etapas da MEAC) e a interpretação da percepção dos usuários através da constelação de atributos. $A$ conclusão evidencia que não considerar a opinião dos usuários torna a leitura ambiental deficiente, podendo gerar falsos diagnósticos e recomendações incoerentes às necessidades reais.
\end{abstract}

Palavras chave: Percepção ambiental; Constelação de atributos; Interpretação de dados.

\begin{abstract}
The environmental perception is one of the leading generators of data for a correct reading of an environment in use. The interpretation of testimonials from users is key to optimizing environment and system. After applying the systemic approach of the built environment- MEAC in the food court of a shopping mall, this article presents the comparative results between the interpretation of physical data (through the first 3 stages of MEAC) and the interpretation of the perception of the users through the perception tool called constellation of attributes. The conclusion shows that not consider the views of users makes poor environmental reading, can generate false diagnoses and inconsistent recommendations to the real needs.
\end{abstract}




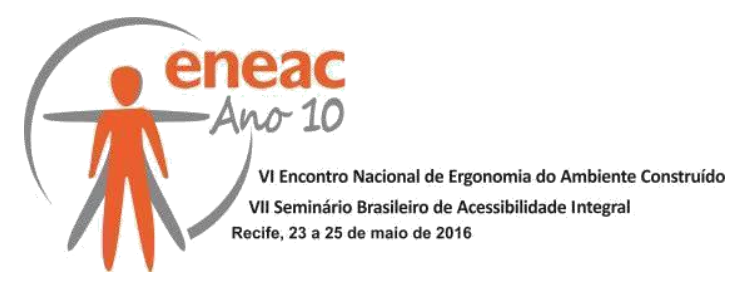

\section{INTRODUÇÃO}

Na ergonomia do ambiente construído, os estudos se concentram na relação entre o usuário e o espaço, reunindo estudos ligados às disciplinas relacionadas ao ser humano e ao ambiente físico. As pesquisas dessa vertente da ergonomia incorporam desde a antropologia, antropometria, sociologia e psicologia, como também a arquitetura, engenharia e design (MARTINS et al, 2006).

Enfatizando esta multidisciplinaridade, Villarouco (2007) cita que a ergonomia do ambiente construído vai além das questões arquitetônicas, pois tem como foco a adaptabilidade $e$ conformidade do espaço às tarefas e atividades que neles irão se desenvolver. A autora complementa chamando a atenção para a importância da percepção que o usuário tem para com o ambiente e seus sentimentos, evidenciando a importância das questões cognitivas.

Um ambiente, qualquer que seja ele, faz parte de um sistema complexo formado por questões estruturais, sistemáticas, sociais, cognitivas, etc. Para se analisar ergonomicamente um ambiente é fundamental compreender a relação estabelecida entre as configurações físicas (formada pelos elementos tangíveis que a compõe) e os aspectos cognitivos que envolvem sua percepção pelos usuários (que compreendem os elementos intangíveis).

Logo, avaliar a estrutura de um ambiente público apenas sob a ótica da infraestrutura, ou ainda a partir do olhar de um único indivíduo, pode gerar diagnósticos imprecisos e que muito provavelmente não atenderão as necessidades da coletividade.

O objetivo desse trabalho é fazer uma comparação entre duas opiniões sobre a utilização de uma praça de alimentação de um shopping center. A primeira opinião é individual e pertence a um ergonomista após a aplicação de parte de uma metodologia ergonômica. Esta opinião possui caráter profissional e contou com o auxílio de dados técnicos. A outra opinião é coletiva e foi obtida junto a 40 usuários deste mesmo ambiente, porém sem as características técnicas e a visão profissional encontrada na outra opinião.

Como resultado foram encontradas opiniões divergentes em algumas questões e chamou a atenção para o fato de se considerar a opinião dos usuários na elaboração de melhorias em ambientes. É importante mencionar uma máxima do design que cita que um designer não projeta para si mesmo, mas sim para um (ou vários) grupos de pessoas. Tomar unicamente suas opiniões como únicas fomentadores do projeto de produtos e ambientes, mesmo que sejam profissionais, é um verdadeiro equívoco e não correspondem as dos demais usuários.

\section{REFERENCIAL TEÓRICO}

Desde sua criação na década de 1940 a ergonomia vem se tornando uma forte aliada na qualidade de vida das pessoas, independentemente da tarefa a ser executada, de sua faixa etária, condição social, física e psicológica. Dentre as diversas áreas de aplicação da ergonomia, o ambiente construído é uma de suas vertentes mais pesquisadas atualmente, tendo em vista que a maioria das tarefas executadas pelo ser humano é realizada dentro de edificações e de áreas construídas, tais como ambientes industriais, comerciais, domésticos, etc.

A visão sistêmica da ergonomia, tendo como foco principal o ser humano e sendo aplicada ao ambiente construído, permite gerar requisitos e parâmetros para planejamento, projeto e 


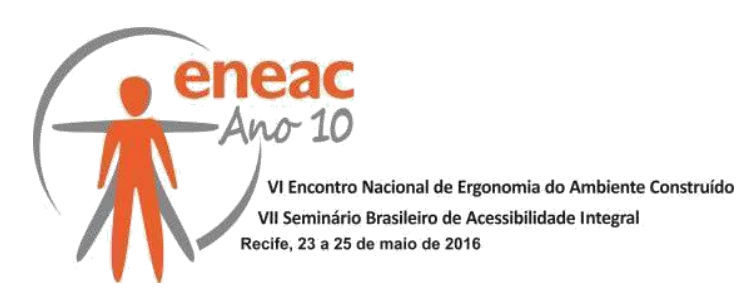

avaliação do ambiente e das tarefas que são executadas em seu interior, garantindo melhorias em seu desempenho (IIDA, 2005). Compreender as características, necessidades e potencialidades dos humanos como parte integrante do sistema Humano $\mathrm{x}$ Tarefa $\mathrm{x}$ Ambiente, torna indispensável o estudo de como os humanos interagem com os ambientes.

Compreendendo o ambiente como algo além da estrutura física, mas um local onde os sentimentos de seus usuários permeiam para o campo do cognitivo e dos sentimentos, é importante inserir brevemente esta discussão no campo da ambiência. De acordo com Augoyard (2004), a ambiência pode ser compreendida como a apropriação das características emocionais e dos sentimentos do ser humano quando este está situado em um ambiente, ou seja, reúne não somente os sentidos "físicos" do ser humano, mas as questões relacionadas a carga emocional que este ambiente proporciona ao usuário.

Neste sentido, o ambiente pode permitir ao usuário sentir-se confortável ou não, ou ainda, satisfeito ou não em estar num determinado ambiente e tornar possível sua permanência ou prolongar sua estadia com prazer em um determinado local. Mesmo diante de algum problema na infraestrutura ou na arquitetura, o ambiente possui uma essência sensível que atrai o ser humano.

Esta essência pode se manifestar em diversas situações: o tipo de decoração adotada, os acontecimentos que ocorrem em seu entorno, a socialização entre as pessoas, a sensação auditiva dos sons do ambiente, o aroma dos alimentos (no caso específico da praça de alimentação), dentre outros. Estas questões vão além da estrutura física do ambiente e a percepção ambiental caminha sob esta égide. Duarte et. al. (2013) informa que ao entrarmos em um ambiente que nos permite percebê-lo com todos os sentidos, nos tornamos capazes de apreender e despertar o processo de reflexão do que este ambiente nos transmite. Portanto, é possuir uma visão muito limitada achar que uma praça de alimentação de um shopping center, cercada por restaurantes e lojas por todos os lados, é um simples local para se alimentar.

Neste caso, acreditar que um único usuário (no caso, o profissional de ergonomia que está analisando ergonomicamente o ambiente) pode reconhecer o local, determinar pontos negativos e positivos e determinar melhorias a serem usufruídas por todos os demais usuários é possuir uma visão muito limitada de percepção ambiental.

Pelas questões tratadas supracitadas, este trabalho busca evidenciar que a união de opiniões, o compartilhamento de experiências e a vivência coletiva do local pode permitir uma compreensão mais completa e condizente com a diversidade de pessoas e sentimentos que estão inseridos nesse local.

Vale mencionar que a análise ergonômica da praça de alimentação foi realizada através da aplicação da Metodologia Ergonômica para o Ambiente Construído - MEAC, proposta por Villarouco (2008). Esta metodologia consiste na considera os aspectos físicos e cognitivos dos usuários. É dividida em cinco etapas, sendo as três primeiras relacionadas as questões físicas de infraestrutura, quarta ligada as questões cognitivas e a quinta corresponde ao diagnóstico das quatro anteriores. Desta forma permite uma compreensão global do ambiente, permitindo a geração de recomendações mais precisa e completa.

A análise ergonômica da praça de alimentação e a aplicação das etapas da MEAC ocorrem de maneira transversal, ou seja, foram pontuais e a coleta de dados ocorreu em dois dias, pois o objetivo era coletar as informações durante um horário de grande fluxo, no caso, o horário do almoço. Quanto ao emprego da ferramenta de percepção do usuário, diversas pessoas foram abordadas e algumas decidiram participar. A seleção de pessoas para participar foi aleatória, sem nenhuma restrição ou características específica a ser observada. 


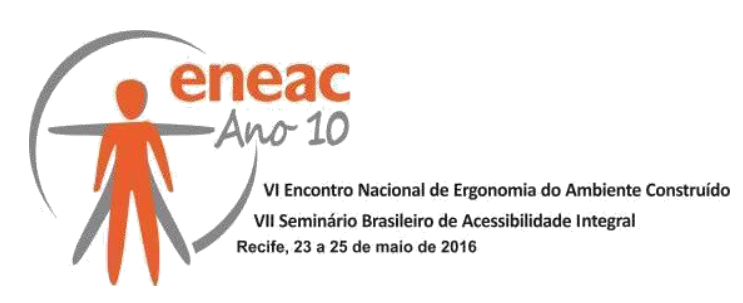

\section{ESTUDO DE CASO - PRAÇA DE ALIMENTAÇÃO DE UM SHOPPING CENTER}

Este trabalho ocorreu durante a avaliação ergonômica do ambiente construído em uma praça de alimentação de um shopping center na cidade de Caruaru, no estado de Pernambuco, Brasil. O objetivo da pesquisa foi gerar informações sobre o ambiente de caráter alimentício para posterior geração de melhorias.

Conforme mencionado anteriormente, foi utilizada a MEAC como metodologia ergonômica e a coleta de dados ocorreu conforme suas etapas De acordo com os preceitos dessa metodologia, a avaliação é realizada em três fases:

- $\quad$ Fase de aspectos físicos e técnicos: abrange as três primeiras etapas da MEAC, que compreendem: 1) Visão do profissional (Análise global do ambiente); 2) Os dados técnicos e mensuráveis (Identificação da Configuração Ambiental); 3) usabilidade do ambiente (análise do ambiente em uso);

- Fase dos aspectos cognitivos: corresponde a percepção dos usuários. Neste trabalho foi utilizada a ferramenta Constelação de Atributos.

- Fase de diagnóstico: compreende a análise geral e comparação dos resultados encontrados nas quatro análises anteriores. Esta etapa final é o ponto chave da MEAC, pois incorpora o resultado das duas fases anteriores e delineia um panorama geral das três análises físicas e da análise cognitiva, confrontando-as com o objetivo de se chegar a uma concordância de ideias. Este consenso permite a geração de recomendações condizentes conforme a análise global.

\subsection{Geração de categorias}

Para facilitar a compreensão das respostas dos usuários após a aplicação da ferramenta de percepção ambiental, a ferramenta constelação de atributos recomenda a categorização das respostas através do agrupamento de atributos por classes de mesma natureza. Esta categorização torna mais compreensível as áreas de conhecimentos a serem acionadas e fomenta as estratégias de geração de melhorias.

Seguindo a mesma ideia de categorização, para este estudo foi adotada a mesma estratégia de uniformização de dados coletados para os resultados das análises dos aspectos físicos, ou seja, as três primeiras etapas da MEAC também tiveram seus resultados categorizados. Desta maneira ficou mais fácil a compreensão dos resultados e a comparação proposta nos objetivos.

É importante citar que a criação de categorias é livre e fica a cargo do profissional ergonomista conforme alguns fatores: sua experiência atuante na área; um mínimo de conhecimento prévio sobre percepção ambiental, percepção cognitiva e interpretação de respostas; além de considerar a configuração do ambiente analisado, o contexto no qual os usuários se encontram e o conteúdo das respostas dos próprios usuários em um determinado intervalo de tempo.

As categorias definidas para análise foram as seguintes: Aspectos organizacionais; Aspectos cognitivos e sociais; Equipamentos e maquinário; Instalações e infraestrutura; Conforto ambiental. Estas categorias foram definidas devido às particularidades do local analisado: uma praça de alimentação localizada em um shopping center, que corresponde a um local de grande interesse da população, geralmente formada por funcionários (vendedores, manutenção, segurança, administrativo e funcionários externos terceirizados) e por visitantes (clientes, pessoas a passeio ou em busca de alimentação). Alguns aspectos particulares de cada categoria são citados a seguir: 


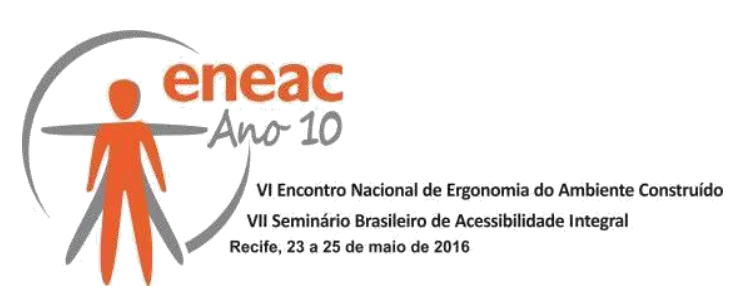

- Instalações e Infraestrutura - corresponde a edificação propriamente dita. A estrutura de alvenaria, com seus acessos (porta, corredor), áreas livres para circulação, piso, teto, paredes, vigas e colunas. São elementos que podem sofrer pequenas alterações devido a sua importância estrutural. Corresponde ao campo de visão macro da arquitetura e da engenharia civil.

- Equipamentos e maquinários - representam os elementos (produtos) constantes na praça de alimentação e que servem para atender as necessidades daqueles que a frequentam. Fazem parte dessa categoria os mobiliários, balcões, cadeiras, placas de sinalização, cercas, bandejas, fornos, freezers, lâmpadas, lixeiras etc.

- Aspectos cognitivos e sociais - compreendem as relações interpessoais e os sentimentos vivenciados pelos frequentadores do local. Devido a grande quantidade de respostas subjetivas ligadas aos sentimentos pessoais foi necessário criar uma categoria que abrangesse estas questões.

- Conforto ambiente - esta categoria compreende os aspectos relacionados a temperatura local, a acústica e a iluminação. Durante a etapa de avaliação dos aspectos físicos, mais precisamente na segunda etapa da MEAC, chamada configuração ambiental, estas medidas foram obtidas através do uso dos seguintes equipamentos técnicos: Luxímetro digital da marca Minipa, modelo MLM-1011; Decibelímetro digital da marca Minipa, modelo MSL-1325; Termo anemômetro digital da marca Minipa, modelo MDA-II. Todos os equipamentos estavam devidamente calibrados.

A tabela 1 resume a categorização das respostas, cita as situações condizentes com a categoria e a cor adotada na constelação de atributos.

\section{Tabela 1 - Resumo das categorias escolhidas}

\begin{tabular}{|c|c|}
\hline CATEGORIA & COR \\
\hline $\begin{array}{c}\text { Aspectos } \\
\text { organizacionais }\end{array}$ & \\
\hline $\begin{array}{c}\text { Aspectos } \\
\text { cognitivos/sociais }\end{array}$ & \\
\hline $\begin{array}{c}\text { Equipamentos e } \\
\text { maquinário }\end{array}$ & \\
\hline $\begin{array}{c}\text { Instalações e } \\
\text { infraestrutura }\end{array}$ & \\
\hline Conforto \\
ambiental & \\
\hline \hline
\end{tabular}

Fonte: elaborada pelos autores

É importante destacar que uma praça de alimentação de um shopping center é um local que oferece ambientes para prática comercial ligada ao setor de alimentação e que geralmente localiza-se em posição central, circundado por ambientes comerciais de vendas de produtos ou serviços. Logo, pessoas que não necessariamente frequentam o local em busca de alimentação também frequentam a praça de alimentação na condição de transeunte, a passeio, diversão e socialização. 


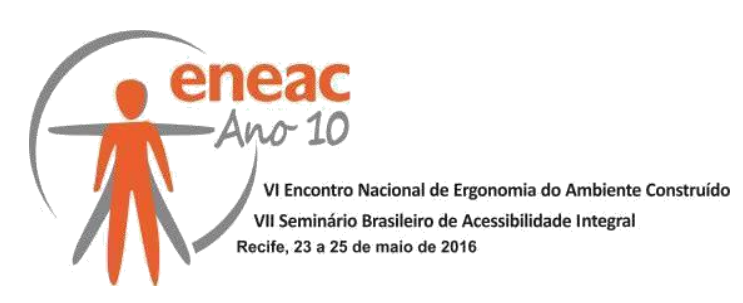

\subsection{Resultado das análises dos aspectos físicos}

Após a realização da primeira etapa da MEAC, a Análise Global do Ambiente, o profissional de ergonomia encontrou a seguinte situação:

- Desorganização das mesas.

- Ambiente externo (no entorno da praça de alimentação) considerado bom.

- Circulação de pessoas deficiente em algumas partes.

- Acabamento da alvenaria deficiente (rebocos e goteiras em alguns locais).

- Os materiais de revestimento dos mobiliários são adequados para facilitar a limpeza.

- Local bem ventilado e bem iluminado.

- Presença de divisórias desnecessárias.

Depois da análise da identificação da configuração ambiental, onde foi possível utilizar equipamentos técnicos de medição, os resultados encontrados foram os seguintes:

- Fluxo de pessoas deficiente durante a avaliação, que ocorreu no horário de pico.

- Em alguns locais o mobiliário não permite uma circulação adequada conforme recomendações da NBR9050 (2015).

- O local possui temperatura condizente com a norma regulamentadora NR-17.

- Os ruídos em 6 dos 10 pontos de medição estão acima do recomendado pela norma 10152 (2010).

- O detalhamento do layout mostrou organização na estrutura dos restaurantes e na área destinada as mesas.

- Não foi possível obter a planta baixa do local, portanto o layout foi desenvolvido a mão livre.

A análise do ambiente em uso correspondeu à terceira etapa da MEAC. Com o intuito de preservar a imagens dos funcionários, clientes e empresa, não foi exibida nenhuma imagem coletada nesta etapa. Os resultados encontrados foram os seguintes:

- Ambiente bastante movimentado (o horário de análise desta etapa ocorreu entre 12:30 e 14:00)

- Disposição das mesas em alguns pontos atrapalha circulação

- Locomoção dos transeuntes é dificultada nos locais de cruzamento entre as áreas de circulação e os espaços destinados às mesas, de frente aos restaurantes.

- As atividades dos funcionários no interior dos restaurantes ocorrem de maneira correta.

- Tarefas internas realizadas pelos funcionários no interior dos estabelecimentos ocorreram de maneira satisfatória. Todos estavam bem uniformizados e havia equipamentos de segurança devidamente sinalizados.

- $\quad \mathrm{Na}$ área da praça de alimentação destinada ao público havia equipamentos de segurança para proteção individual e coletiva. 


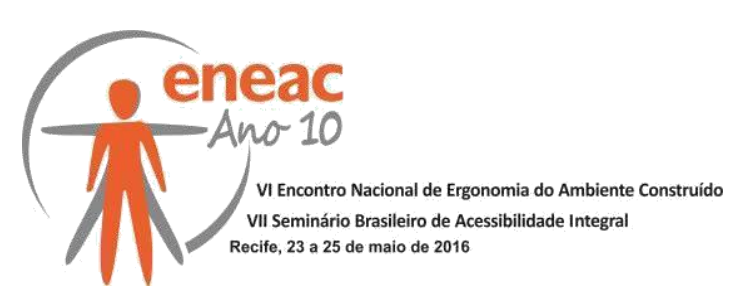

- A grande maioria dos ruídos encontrados na praça de alimentação correspondeu às conversas paralelas entre os clientes.

- Diversos clientes não recolhem suas bandejas após as refeições. Esta atitude dificulta a utilização das mesas pelos novos clientes e exige dos funcionários da limpeza uma movimentação intensa entre as mesas.

- Quase todos os funcionários dos restaurantes trabalham em pé, salvo alguns que exercem a função de caixa.

- A hora de escolha dos pratos e de pagamento atrapalha a circulação. Isto ocorre porque a posição dos caixas dos restaurantes está voltada para as áreas de circulação da praça de alimentação. Então quando os clientes estão escolhendo seus pratos e pagando, ficam parados nas áreas de circulação, atrapalhando o fluxo.

- O fato das mesas e cadeiras serem fixas mantem o layout inalterado e evita uma possível desorganização maior.

Os resultados obtidos nas três etapas de aspectos físicos evidenciaram diversas situações que o profissional de ergonomia, design de interiores ou arquitetura poderá considerar na preparação do diagnóstico e na geração de melhorias. Os resultados correspondem a três pontos de vista diferentes:

- Etapa 1 da MEAC: a visão preliminar e de reconhecimento do profissional;

- Etapa 2 da MEAC: averiguação por instrumentação e medições das questões mais impactantes encontradas na etapa anterior;

- Etapa 3 da MEAC: verificação da usabilidade e do desempenho das atividades.

Embora a quantidade de informações obtidas seja relevante, sendo possível identificar as questões positivas e negativas do ambiente quanto a sua infraestrutura, execução de tarefas e fluxo de pessoas, tais dados não permitem uma leitura completa e conclusiva das condições e necessidades de uso do ambiente, nem se atendem as necessidades daqueles que o frequentam e consequentemente acabem deixando lacunas nos diagnósticos.

Esta constatação ocorre porque a leitura das três primeiras fases da MEAC é feita por apenas uma pessoa, no caso, o profissional ergonomista, designer de interiores ou arquiteto. Esta condição reflete o ponto de vista de apenas um indivíduo que embora seja um profissional ligado a infraestrutura e a prática de ergonomia do ambiente construído, sua visão não reflete a opinião geral dos usuários. Não importa se estes usuários tenham ou não conhecimento sobre arquitetura ou ergonomia, mas eles são os principais atores no sistema Humano $x$ Tarefa $x$ Ambiente. Lembrando que o foco principal das intervenções ergonômicas e dos projetos de arquitetura e design de interiores é o ser humano.

\subsection{A importância da opinião dos usuários}

A praça de alimentação é frequentada por uma quantidade incalculável de pessoas, com diferenças nos mais diversos aspectos, tais como estrutura corporal, idade, sexo, condições físicas e cognitivas, grau de instrução, motivos de frequência, necessidades do uso do ambiente, etc. Portanto, cada pessoa que a frequenta tem uma opinião diferente e pessoal sobre sua experiência de uso. Para enfatizar estas questões, Flores e Ulbricht (2008) citam que o usuário de um ambiente é considerado único na percepção ambiental, pois ele experimenta sensações diversas e as compreende conforme seus sentidos e suas condições a nível fisiológico, psicológico e físico. 


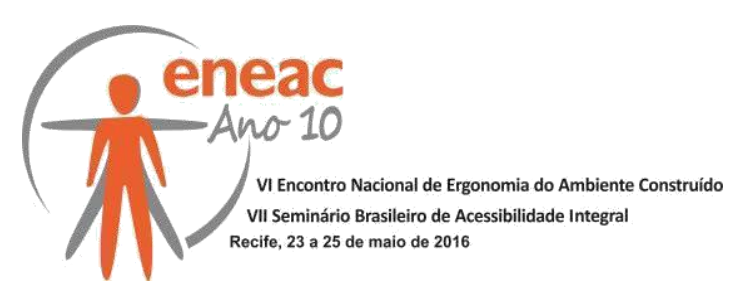

Okamoto (2002) reforça que o processo de compreensão e identificação do meio ambiente ocorre de modo integral pelo ser humano, ou seja, ele utiliza todos os seus sentidos de maneira integrada, juntamente com seu repertório e conhecimentos abstratos e simbólicos, tornando sua experiência e leitura do ambiente um momento íntimo e individual.

Neste sentido, para evitar uma única leitura ergonômica do ambiente em análise, que pode gerar uma leitura equivocada, a MEAC dispõe de uma etapa de percepção dos usuários. Conforme cita Villarouco (2013), esta etapa demanda conhecimentos prévios sobre psicologia ambiental, percepção ambiental e ergonômica cognitiva, uma vez que há necessidade de adoção de ferramentas auxiliares na identificação de variáveis de caráter mais cognitivo, perceptual.

Para obtenção da percepção dos usuários foi utilizada a ferramenta constelação de atributos. Idealizada por Moles em 1968, esta ferramenta busca auxiliar no conhecimento da consciência psicológica do usuário frente ao espaço que ele utiliza. Esta ferramenta possui diversas vantagens:

- Método de coleta simples, rápido e descentralizado, pois pode ser obtido por qualquer pessoa que frequente um ambiente;

- Maior liberdade de expressão dos usuários, pois as perguntas são abertas;

- Interpretação por representação gráfica legível, onde é possível obter uma "imagem da percepção";

- As perguntas exigem dos entrevistados respostas que trazem uma contradição crítica sobre a visão do ambiente, pois ele responde a duas perguntas distintas, sendo uma de caráter subjetiva e desejado, e outra de caráter objetiva e real.

\subsection{A constelação de atributos}

Foram entrevistados cinquenta usuários da praça de alimentação entre 10:00 e 12:00. As perguntas foram: 1) quando você pensa em uma praça de alimentação, quais imagens e palavras vêm a sua mente? 2) quando você pensa na sua praça de alimentação, quais imagens e palavras vêm a sua mente?

A primeira pergunta pede respostas relacionadas à expectativa de uso de um ambiente imaginário, identificando aspectos que o usuário deseja, ou seja, um ambiente considerado ideal e que o satisfaça em diversos sentidos. Esta pergunta obteve ao todo 121 respostas, chamadas de atributos ideias de uma praça de alimentação. Já a segunda pergunta requer respostas de cunho objetivo, onde o entrevistado irá falar sobre a praça de alimentação que está frequentando, opinando através de uma visão real. Esta pergunta obteve 99 respostas chamadas de atributos reais da sua praça de alimentação. A Figura 1 a seguir exibe as tabela com os atributos, lado a lado, estruturadas por:

- Coluna 1 - cores representando as categorias de atributos, devidamente separados conforme a categorização estabelecida e relatada anteriormente;

- Coluna 2 - Os atributos relatados pelos usuários;

- Coluna 3 - quantidade em que o atributo foi citado;

- Coluna 4 - sua classificação.

As colunas de probabilidade de aparecimento e de distância psicológica não foram inseridas na tabela por não contribuírem com os propósitos desse artigo. 


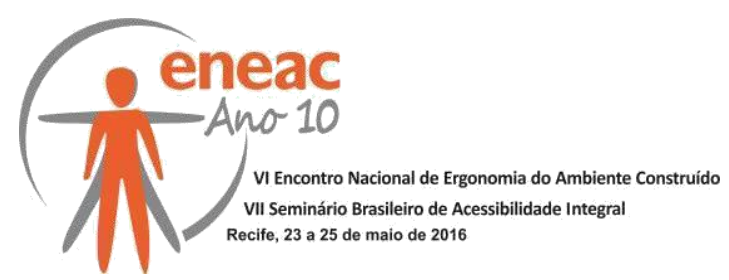

Figura 1 - Tabelas de atributos ideais e reais da praça de alimentação

\begin{tabular}{|c|c|c|c|}
\hline \multicolumn{4}{|c|}{ Ambiente IDEAL - praça de alimentação } \\
\hline CAT./COR & ATRIBUTOS & QUANT. & CLASS. \\
\hline & lluminação boa & 17 & 1 \\
\hline & Circulação (movimentação/distribuição móveis) & 13 & 2 \\
\hline & Cadeiras/assentos (confortável/aconchegante) & 10 & 3 \\
\hline & Cores (neutras/suaves/vibrantes) & 6 & 4 \\
\hline & Aconchegante (ambiente/lugar) & 6 & 4 \\
\hline & Conforto & 6 & 4. \\
\hline & Alimentação (variedade/rapidez) & 5 & 5 \\
\hline & Espaçoso (espaço maior) & 5 & 5 \\
\hline & Bom/rápido atendimento & 4 & 6 \\
\hline & Acessivel & 3 & 7 \\
\hline & Bancada acessivel (grande expositor/alimentos & 3 & 7 \\
\hline & Climatizado (conforto térmico) & 3 & 7 \\
\hline & Espaço (reservado/VIP real) & 3 & 7 \\
\hline & Limpo (móveis) & 3 & 7 \\
\hline & Interatividade/prazer/confraternização & 3 & 7 \\
\hline & Móveis (modernos/resistente/seguro) & 3 & 7 \\
\hline & Ventilação boa (refrigerado) & 3 & 7 \\
\hline & Visual (confortável/limpo/estética) & 3 & 7 \\
\hline & Agradável & 2 & 8 \\
\hline & Ambiente harmonioso/atrativo & 2 & 8 \\
\hline & Logomarca/sinalização & 2 & 8 \\
\hline & Piso com revestimento adequado & 2 & 8 \\
\hline & Preço acessivel & 2 & 8 \\
\hline & Seguro & 2 & 8 \\
\hline & Silencioso (revestimento acústico) & 2 & 8 \\
\hline & WC deficientes & 1 & 9 \\
\hline & Plantas decorativas & 1 & 9 \\
\hline & Organização & 1 & 9 \\
\hline & Música ambiente (lugar com música) & 1 & 9 \\
\hline & Mesa tipo ilha & 1 & 9 \\
\hline & Conforto ergonômico & 1 & 9 \\
\hline & Ambiente limpo & 1 & 9 \\
\hline & Balcão grande & 1 & 9 \\
\hline & TOTAL DE RESPOSTAS & 121 & \\
\hline
\end{tabular}

\begin{tabular}{|c|c|c|c|}
\hline \multicolumn{4}{|c|}{ Ambiente REAL - praça de alimentação } \\
\hline \multirow[t]{28}{*}{ CAT./COR } & ATRIBUTOS & QUANT. & CLASS. \\
\hline & cadeiras/assentos desconfortáveis & 15 & 1 \\
\hline & Iluminação (deficiente/fraca/muito clara/f & 12 & 2 \\
\hline & Circulação ruim & 10 & 3 \\
\hline & Mesas (desconfortáveis/insuficiente/várias & 7 & 4 \\
\hline & Cores (fortes/aleatória) & 6 & 5 \\
\hline & Desconfortável & 5 & 6 \\
\hline & Espaço pequeno (não aproveitado) & 5 & 6 \\
\hline & Não Atrativo/agradável/aconchegante & 4 & 7 \\
\hline & Mesas (má organização) & 4 & 7 \\
\hline & Atendimento (regular/mau) & 3 & 8 \\
\hline & Inacessivel & 2 & 9 \\
\hline & Agoniado / arriscado & 2 & 9 \\
\hline & Alimentos (baixa qualidade e variedade) & 2 & 9 \\
\hline & Apertado & 2 & 9 \\
\hline & Má distribuição (caixas/alimentos no bald & 2 & 9 \\
\hline & Barulhenta & 2 & 9 \\
\hline & Cadeiras (acumuladas/insuficientes) & 2 & 9 \\
\hline & Desagradável/desconvidativa & 2 & 9 \\
\hline & Espaço reservado/exclusividade (falta) & 2 & 9 \\
\hline & Preços altos & 2 & 9 \\
\hline & Quente (espaço interno quente) & 2 & 9 \\
\hline & Ventilação (frio) & 2 & 9 \\
\hline & Iluminação interna boa & 1 & 10 \\
\hline & Mesas com espaço ideal & 1 & 10 \\
\hline & Organização ruim & 1 & 10 \\
\hline & Visual desconfortável & 1) & 10 \\
\hline & TOTAL DE RESPOSTAS & 99 & \\
\hline
\end{tabular}

Abaixo estão as constelações de atributos. Embora as imagens sejam pequenas, elas servem para compreensão do resultado final sem a necessidade de detalhamento, pois não faz parte dos objetivos desse trabalho. A constelação da esquerda representa o ambiente IDEAL e a da esquerde representa o ambiente REAL.

Figura 2 - As constelações de atributos geradas IDEAL e REAL
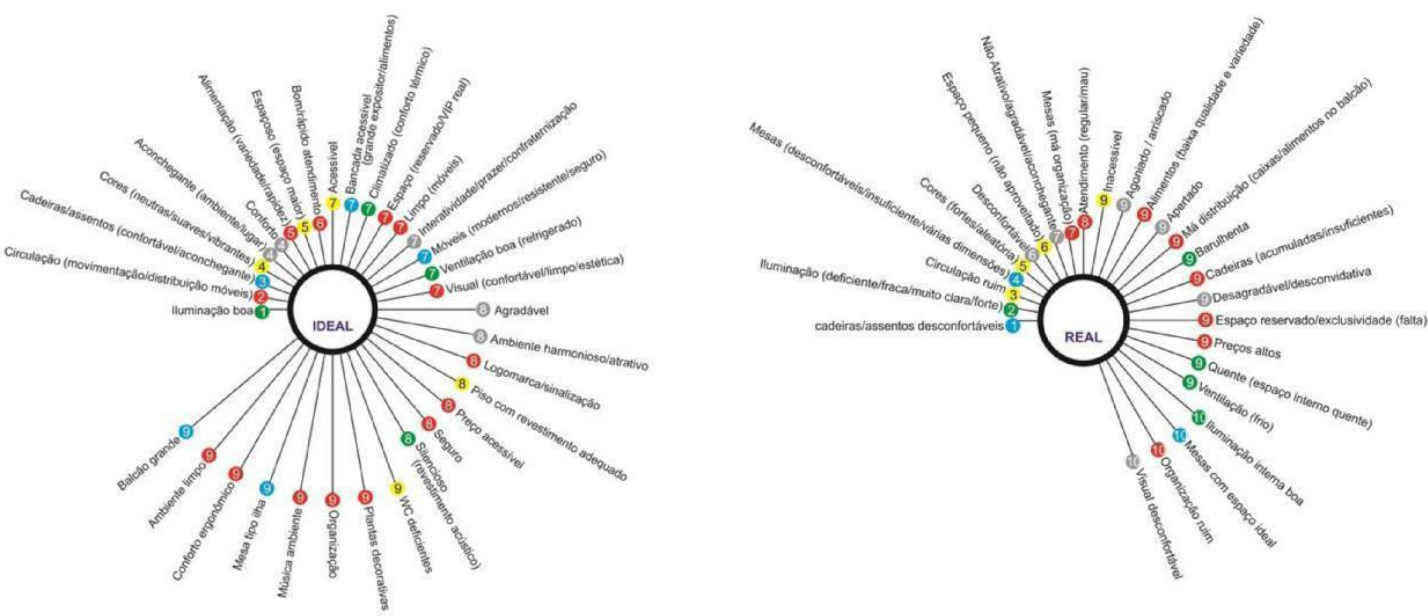


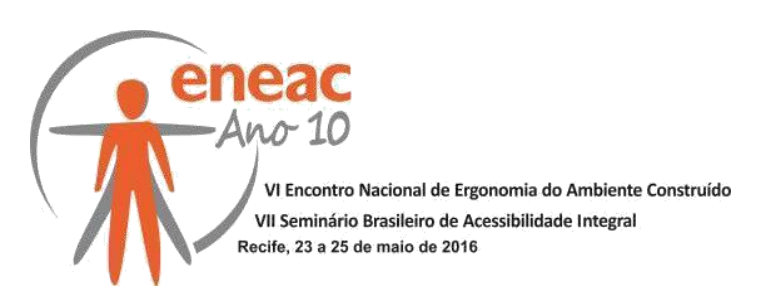

\section{COMPARAÇÃO DOS RESULTADOS FíSICOS E COGNITIVOS}

Enquanto o tópico 3.2 (resultado das análises dos aspectos físicos) exibiu algumas das conclusões encontradas pelo profissional de ergonomia, conforme a metodologia aplicada e sua interpretação técnica e o uso de instrumentos, o tópico 3.4 (a constelação de atributos) trouxe a opinião dos usuários do ambiente, de maneira despretensiosa, sem uma visão profissional e aprofundada do ambiente, mas sim como um simples frequentador do local. A opinião dos usuários foi dividida em duas partes, conforme os procedimentos metodológicos da constelação de atributos. A tabela 2 mostra os resultados obtidos, em porcentagem, da quantidade de atributos identificados por três pareceres.

Tabela 2 - Tabela com os pareceres por categorias

\begin{tabular}{|c|l|c|c|c|}
\hline \multirow{2}{*}{ COR } & \multirow{2}{*}{ Categorias de atributos } & \multirow{2}{*}{$\begin{array}{c}\text { Opinião } \\
\text { profissional }\end{array}$} & \multicolumn{2}{|c|}{ Opinião usuário } \\
\cline { 3 - 5 } & & IDEAL & REAL \\
\hline & & $51 \%$ & $35 \%$ & $18 \%$ \\
\hline & Aspectos organizacionais & $5 \%$ & $17 \%$ & $14 \%$ \\
\hline & Aspectos cognitivos/sociais & $10 \%$ & $14 \%$ & $24 \%$ \\
\hline & Equipamentos e maquinário & $15 \%$ & $14 \%$ & $24 \%$ \\
\hline & Instalações e infraestrutura & $19 \%$ & $20 \%$ & $20 \%$ \\
\hline
\end{tabular}

Algumas questões chamaram atenção e para facilitar, esta leitura dos resultados será feita em cinco etapas, conforme as categorias dos atributos:

- Aspectos organizacionais - Esta categoria liderou a opinião tanto do profissional ergonomista quanto dos usuários e seu desejo por um ambiente IDEAL. Quanto ao ambiente REAL dos usuários, esta categoria ficou apenas em terceiro, com $18 \%$ do total. Isto reflete uma combinação positiva entre a visão técnica do ergonomista e o desejo dos usuários e é um fator a ser trabalhado na geração de melhorias. No entanto não é um aspecto tão relevante e notável pelos usuários em sua vivência REAL da praça de alimentação.

- Aspectos cognitivos/sociais - Os aspectos cognitivos correspondem as relações e sentimentos entre os usuários. Esta categoria ficou em último lugar entre as respostas e observações do profissional, afinal o foco é na análise física do ambiente. Quanto a opinião REAL e IDEAL dos usuários, os atributos dessa categoria ocupam posições intermediárias, mas relevantes.

- Equipamentos e maquinários - o profissional observou os atributos ligados aos equipamentos por fazerem parte do Sistema Humano-Tarefa-Máquina conforme a abordagem ergonômica necessária para uma real avaliação do local. Porém, para a praça de alimentação, estas observações ocuparam apenas o quarto lugar. O que chamou atenção foi que esta categoria foi a que possui a maior quantidade de atributos do usuário real, ou seja, a qualidade dos equipamentos é de grande relevância para o dia a dia dos usuários e devem ser trabalhados pelo ergonomista em suas recomendações.

- Instalações e infraestrutura - esta categoria também está na liderança dos usuários quanto as suas opiniões REAIS. Quanto ao desejo por um ambiente IDEAL, os 


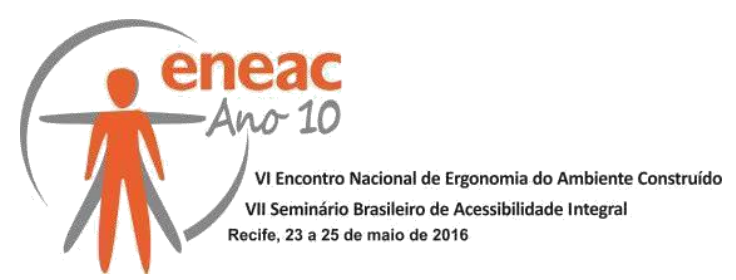

atributos desta categorias estão em penúltimo lugar. $E$ com relação às observações do ergonomista, esta categoria ocupa uma posição mediana.

- Conforto ambiental - Esta foi a única categoria onde houve consenso na quantidade de atributos. Ocupando uma posição de relevância, obteve o segundo lugar em todos os três pareceres.

\section{RESULTADOS}

Foi possível observar que gerar recomendações de melhorias optando apenas pela opinião de um profissional pode não corresponder as reais necessidades dos usuários, comparando com o parecer REAL. Bem como também podem não atender aos desejos dos usuários, comparando o parecer IDEAL.

As questões que envolvem a relação Humano x Ambiente são muito complexas e não podem ficar apenas sob a ótica física e técnica. Sempre haverá a necessidade da empatia e da interpretação da opinião de outros usuários. Os resultados mostraram conflitos de interesses e pontos de vista diferentes entre o profissional de ergonomia e a opinião dos usuários a ponto da penúltima categoria determinada pelo ergonomista ser a primeira e mais relevante categoria para os usuários e suas experiências REAIS.

Que este exemplo sirva para pontuar uma questão de grande importância no desenvolvimento de produtos e ambientes: considerar a opinião dos usuários nas etapas da ergonomia conceptiva (ou corretiva), com o intuito de gerar um projeto mais coeso, adequado aos desejos, necessidades e limitações dos usuários.

\section{REFERÊNCIAS BIBLIOGRÁFICAS}

AUGOYARD, Jean-François. Vers une esthétique des Ambiances. In: AMPHOUX, Pascal; THIBAUD, Jean-Paul et CHELKOFF, Grégoire. Ambiances en Débat. Bernin : À La Croisée, 2004 pp. 7-30

ASSOCIAÇÃO BRASILEIRA DE NORMAS TÉCNICAS - ABNT. NBR 5413 - lluminância de Interiores. Rio de Janeiro, 1992;

NBR 9050 - Acessibilidade a edificações, mobiliário, espaços e equipamentos urbanos. Rio de Janeiro, 2015;

NBR 10152 - Nível de ruído para conforto acústico. Rio de Janeiro, 2010;

BRASIL, Ministério do Trabalho e Emprego. Normas Regulamentadoras de Segurança e Medicina do Trabalho. NR 17 Ergonomia. Rio de Janeiro, 1978.

DUARTE, C.R.; COHEN, R.; BRASILEIRO, A.; LIRA, E. "ACESSIBILIDADE PLENA" A MUSEUS:

perspectivas de uma acessibilidade cultural, sensorial e emocional. In: Anais do IV Encontro Nacional de Ergonomia do Ambiente Construído - ENEAC. Florianópolis, 2013.

FLORES, Ângela R. B.; ULBRICHT, Vânia R.; ZANCHETT, Pedro S. Terceira idade e moradia. In: Anais do XV Congresso Brasileiro de Ergonomia - ABERGO. Porto Seguro - Bahia, 2008.

IIDA, Itiro. Ergonomia - Projeto e Produção. $2^{\underline{a}}$ edição revista e ampliada. São Paulo: Edgard Blücher, 2005.

MARTINS, L. M. et al. Análise ergonômica comparativa de cozinhas residenciais com arranjos físicos diferenciados. In Congresso Internacional de Ergonomia e Usabilidade de Interfaces Humano-Tecnologia. 6, São Paulo. Anais... ERGODESIGN. Bauru. 2006.

OKAMOTO, J. Percepção ambiental e comportamento. São Paulo: Mackenzie, 2002.

VILLAROUCO, V. Construindo uma metodologia de avaliação ergonômica do ambiente. In: 


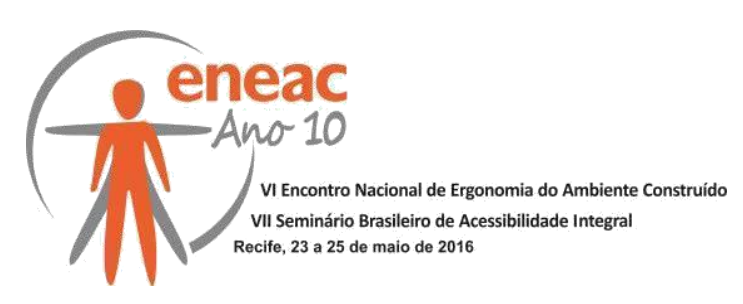

Anais do XV Congresso Brasileiro de Ergonomia - ABERGO. Porto Seguro - Bahia, 2008.

VILLAROUCO, V. Ergonomia do Ambiente Construído. 8 Curso de Especialização em Ergonomia. Universidade Federal de Pernambuco. Notas de sala de aula, 2013.

VILLAROUCO, V. Reflexões acerca da Ergonomia do Ambiente Construído. In: BOLETIM DA ASSOCIAÇÃO BRASILEIRA DE ERGONOMIA. Recife: ABERGO, 2007. 